\title{
Effects of Frequent Shearing on Root Growth and Mycorrhizal Colonization of Two Landscape Shrubs
}

\author{
Chris A. Martin ${ }^{1}$ \\ Department of Applied Sciences and Mathematics, Arizona State University, \\ 6073 S. Backus Mall, Mesa, AZ 85212
}

\author{
Sean A. Whitcomb \\ Plant Biology Graduate Program, School of Life Sciences, Arizona State \\ University, Tempe, AZ 85287
}

Jean C. Stutz

Department of Applied Sciences and Mathematics, Arizona State University, 6073 S. Backus Mall, Mesa, AZ 85212

Additional index words. carbon assimilation, landscape management, leaf conductance, pruning, soil respiration

\begin{abstract}
Leucophyllum frutescens I. M. Johnst. (Texas sage) and Nerium oleander L. (oleander) shrubs grown for 2 years in the southwest United States under well-watered conditions in outdoor field plots were either sheared every 6 weeks or not pruned (control) to determine if frequent shearing had an effect on root growth and mycorrhizal colonization. During February and June of the second year after transplanting, leaf gas exchange, shoot and root growth, and arbuscular mycorrhizal fungi (AMF) colonization of shrubs were studied. Shearing reduced shrub volume of Texas sage and oleander by $84 \%$ and $82 \%$, respectively. Leaf carbon assimilation (A) and conductance of both shrub taxa were stimulated by frequent shearing, especially during June. Shearing decreased root mass density (RMD) and root length density (RLD) of Texas sage but had no impact on RMD or RLD of oleander. Shearing decreased the length of Texas sage roots colonized by AMF but increased AMF colonization of oleander roots. Soil respiration and temperatures were less under all shrubs that were frequently sheared than those that were not pruned and were higher under all shrubs in June than in February. From these data we conclude that under well-watered conditions, the rejuvenative capacity and resilience of oleander to the practice of frequent shearing is greater than Texas sage and recommend that Texas sage shrubs not be frequently sheared in southwest landscapes.
\end{abstract}

Pruning is an integral management practice for controlling growth of woody shrubs in urban landscapes. In arid cities such as Phoenix, AZ, the practice of frequent shearing is often used to train shrubs into geometric shapes as a result of a number of factors, including overplanting and human aesthetic preferences (Martin, 2008; Martin et al., 2003). The impact that frequent shearing of foliage from landscape shrubs has on the below-ground allocations of carbon to roots is not well understood, although limited studies of woody plants in agroforesty systems suggest that pruning generally has a negative impact on root length density and/or fine root growth (Bayala et al., 2004;

Received for publication 17 June 2010. Accepted for publication 19 Aug. 2010.

This material is based on work supported by the National Science Foundation under Grant No. DEB-0423704, Central Arizona-Phoenix LongTerm Ecological Research (CAP LTER).

We thank Linda Stabler for assistance at the experimental field site.

${ }^{1}$ To whom reprint requests should be addressed; e-mail chris.martin@asu.edu.
Peter and Lehmann, 2000; Wildy and Pate, 2002).

Many plants in arid environments, including common landscape trees and shrubs, form associations with arbuscular mycorrhizal fungi (AMF) (Cousins et al., 2003). Plants can allocate an estimated $35 \%$ to $80 \%$ of the carbon fixed in photosynthesis below ground for root production and respiration, mycorrhizae, and root exudates (Davidson et al., 2002; Raich and Nadelhoffer, 1989; Ryan and Law, 2005). Soil respiration is the major pathway for carbon exiting terrestrial ecosystems, and approximately half of the carbon loss from terrestrial surfaces as $\mathrm{CO}_{2}$ is derived from plant metabolic activity to support and grow roots and associated mycorrhizae (Hanson et al., 2000).

AMF can increase host plant fitness in stressful urban environments by improving nutrient uptake, mitigating drought stress, providing disease resistance, and improving soil structure (Smith and Read, 1997). What is known about the effects of pruning on AMF colonization of roots of woody plants has been gleaned from studies of trees. Ingleby et al. (2007) found that severe pruning of agroforestry trees stimulated colonization of roots by AMF. Stabler et al. (2001) found that AMF can increase tree carbon storage potential in the Phoenix metropolitan area residential landscapes, although this capacity might be somewhat less than in nearby undisturbed desert soils because of a higher carbon cost-to-benefit ratio. The authors have found no previous studies of the effect of frequent shearing of woody shrubs on AMF colonization of shrub roots.

The objective of this study was to determine the effects of the common landscape pruning practice of frequent shearing on root growth and AMF colonization of two shrubs commonly used in landscaping in the southwest United States, Arizona: Leucophyllum frutescens var. green cloud (Texas sage) and Nerium oleander 'Sister Agnus' (oleander). We hypothesized that frequent shearing would reduce root growth, mycorrhizal fungi colonization, and soil respiration of oleander and Texas sage roots because of reductions in carbon allocation to roots brought about by the frequent removal of physiologically mature leaf tissues.

\section{Materials and Methods}

Research was conducted during 2001 at an outdoor field site in Phoenix, AZ (lat. $33^{\circ} 26^{\prime} \mathrm{N}$, long. $112^{\circ} 00^{\prime} \mathrm{W}$ ) to determine effects of the landscape pruning practice of frequent shearing on root growth, AMF colonization, leaf gas exchange, and soil respiration of two regionally common landscape shrubs, variety green cloud ${ }^{\mathrm{TM}} \mathrm{Texas}$ sage (green leaf variant with magenta flowers) and 'Sister Agnus' oleander (semidwarf, whiteflowering clone). The desert climate of Phoenix has an annual average rainfall and potential evapotranspiration of $180 \mathrm{~mm}$ and $2280 \mathrm{~mm}$, respectively.

During May 1999, 18 young, genetically identical, same-source clones of Texas sage and oleander were transplanted from 3.8-L containers into unamended planting holes that were no less than $1.8 \mathrm{~m}$ distance apart. Soil at the field site was a Rillito gravelly loam $\left(\mathrm{pH}=8.1\right.$, carbon $=2500 \mathrm{mg} \cdot \mathrm{kg}^{-1}$, nitrogen $=230 \mathrm{mg} \cdot \mathrm{kg}^{-1}$, phosphorus $=240$ $\mathrm{mg} \cdot \mathrm{kg}^{-1}$ ) with a $0 \%$ to $1 \%$ slope. Mycorrhizal diversity for the field site had been previously reported (Whitcomb and Stutz, 2007). Twelve AMF taxa were detected with Glomus eburneum Kennedy, Stutz \& Morton, Glomus microaggregatum Koske, Gemma \& Olexia, Glomus intraradices Schenck \& Smith, and Glomus mosseae (Nicolson \& Gerd.) Gerd. \& Trappe the most frequently detected.

All shrubs were fertilized each spring with $200 \mathrm{~g}$ of controlled-release fertilizer $20 \mathrm{~N}-4.4 \mathrm{P}-4 \mathrm{~K}$ plus micronutrients (Best Paks $^{\mathrm{TM}}$; J.R. Simplot Co., Boise, ID). The ground surface at the field site was without surface mulch and was kept weed-free by an application of XL 2G (DowElanco Speciality Products, Indianapolis, IN) pre-emergent herbicide in Spring 2000 and hand-weeding. Supplemental water was delivered once per week by an automated drip irrigation system 
to each shrub through two $3.8-\mathrm{L} \cdot \mathrm{h}^{-1}$ emitters at an average rate of $1730 \mathrm{~L}$ of water/shrub/ year. The irrigation rate was based on a previous assessment of irrigation application rates by local residents and was deemed wellwatered (Martin, 2001).

During 2000-2001, shrubs were either sheared into a box shape with handheld hedge trimmers every 6 weeks or not pruned at all (control). A completely randomized unbalanced experimental design was used with the two pruning treatments randomly assigned to shrubs. The unbalanced design consisted of 12 shrubs frequently sheared and six shrubs not pruned per taxa.

During February and June 2001, the shoots removed by frequent shearing were collected, dried $\left(60{ }^{\circ} \mathrm{C}\right.$ for $168 \mathrm{~h}$ ), and weighed. Before and after shearing, the size of all shrubs was measured (height, north/south width, east/ west width). Shoot volumes of shrubs were calculated assuming a box shape factor for both shrub taxa. Allometric equations previously developed by Stabler (2003) that predicted the relationship between shoot volume and net primary production of these taxa were used to estimate the percent fraction of shoot mass removed by frequent shearing.

During February and June 2001, soil and roots were collected at a $30-\mathrm{cm}$ distance from the base of each shrub at depths of 0 to $20 \mathrm{~cm}$ and 20 to $40 \mathrm{~cm}$ using a soil auger and placed in self-sealing plastic bags. Samples were kept at $4{ }^{\circ} \mathrm{C}$ until processing. A hydropneumatic root washer (Gillison's, Benzonia, MI) was used to remove roots from a $600-\mathrm{cm}^{3}$ subsample of each soil sample and the wet weight of all live fine roots (less than $2 \mathrm{~mm}$ in diameter) in this subsample was determined. A portion $(\approx 0.1 \mathrm{~g})$ of roots from each subsample was removed, weighed, fixed in $70 \%$ ethanol, and stained in trypan blue (Koske and Gemma, 1989) for quantification of AMF colonization and root length. The remaining roots were dried in an oven for at least $48 \mathrm{~h}$ and weighed. Root mass density (RMD) was calculated as the total root dry weight $/ \mathrm{cm}^{3}$ of soil sampled.

Percent root colonization was determined using the magnified intersections method of McGonigle et al. (1990). Root length of stained roots was estimated using the gridline intersect method of Giovannetti and Mosse (1980). The root length of the stained roots, expressed in centimeters, was used to estimate the of root length of the $600-\mathrm{cm}^{3}$ subsample by using a proportional relationship of the weight of the root sample that was stained to the weight of roots in the $600-\mathrm{cm}^{3}$ subsample. Root length density (RLD) was calculated as the length of roots (centimeters) per cubed centimeter of soil sampled. Total percent root colonization was multiplied by the RLD to determine the length of root colonized per cubed centimeter of soil.

During February and June 2001, measurements of leaf carbon assimilation (A) and conductance $\left(g_{\mathrm{s}}\right)$ and soil respiration were also made. Leaf A and $g_{\mathrm{s}}$ were measured on clear, sunny, calm days during a 3 -h window
( 0830 to $1130 \mathrm{HR}$ ) for maximum local net $\mathrm{CO}_{2}$ assimilation fluxes (Stabler and Martin, 2000). Leaf A and $g_{\mathrm{s}}$ measurements were made with a quarter-liter handheld chamber connected to a LI 6250 portable infrared gas analyzer (IRGA) (LI-COR Biosciences Inc., Lincoln, NE) operating in a closed system mode on the most recently physiologically mature, sun-adapted leaves, three to seven nodes from an apical meristem. Soil respiration was measured during midday under the canopies of all shrubs with a LI 6250 portable IRGA with a soil respiration chamber attachment (LI 6000-09S; LI-COR BioSciences Inc.) plus soil temperature probe. Plastic polyvinyl chloride collars were placed into the soil profile $24 \mathrm{~h}$ before respiration measurement. Coincidently, under canopy, measurements of soil temperature (10-cm depth) were made.

All data were analyzed by shrub taxa using analysis of variance (ANOVA) and Type IV SS because of unequal replication (JMP 6.01; SAS Institute, Cary, NC). No significant differences were noted between the February and June sampling times in the response of root growth and mycorrhizal colonization to treatment, so these data from both sampling dates were pooled. Significance probabilities $(P \leq 0.05)$ and $\mathrm{F}$ ratios were generated for pruning and pruning $X$ depth effects by shrub taxa. RMD and RLD data were analyzed by a two-way ANOVA (depth $\times$ pruning). AMF variables were analyzed after arcsine transformation by a two-way ANOVA (depth $\times$ pruning). Measurements of leaf $\mathrm{A}, g_{\mathrm{s}}$, soil respiration, and soil temperature were analyzed using a twoway ANOVA (month $\times$ pruning). A least squares means Tukey's honestly significant difference test was used to derive the pattern of significant differences between dependent variable responses to pruning treatment effects $(P \leq 0.05)$. For shoot volume data, simple treatment mean values \pm SE were calculated by shrub taxa.

\section{Results and Discussion}

Shearing reduced shrub volume of Texas sage and oleander by $84 \%$ and $82 \%$, respectively (Table 1). The estimated percent fraction of shoot mass removed by frequent shearing was $66 \%$ for Texas sage and $52 \%$ for oleander.

In general, the frequent shearing of Texas sage and oleander shrubs had a stimulatory effect on leaf A (Table 2). Frequent shearing also had a stimulatory effect on leaf $g_{\mathrm{s}}$ of oleander. Leaf $g_{\mathrm{s}}$ of Texas sages was affected by a significant interaction of month and pruning treatment (Table 2). During February, leaf $g_{\mathrm{s}}$ of sheared and unpruned shrubs was similar. However, during June, leaf $g_{\mathrm{s}}$ of unpruned shrubs was $\approx 57 \%$ less than sheared shrubs.

For Texas sage, RMD and RLD were greatest in the top $20 \mathrm{~cm}$ of soil (Table 3 ). The RMD and RLD of unpruned shrubs were 2.1 and 2.4 times greater, respectively, than for frequently sheared shrubs. These results were similar to those of other researchers who found lower RLD (Bayala et al., 2004; Peter and Lehmann, 2000) and lower root mass (Fownes and Anderson, 1991; Wildy and Pate, 2002) for agroforestry trees that had been heavily pruned in comparison with those that were not pruned. A significant interaction between pruning treatments and depth on RMD was found (Table 3). RMD in the top $20 \mathrm{~cm}$ of soil was 1.5 times greater than in the $20-$ to $40-\mathrm{cm}$ depth for sheared

Table 1. Effect of frequent shearing on Leucophyllum frutescens var. green cloud and Nerium oleander 'Sister Agnus' shoot volume $\left(\mathrm{m}^{3}\right)$ during Feb. and June 2001.

\begin{tabular}{lccc}
\hline Month & Treatment & L. frutescens $\left(\mathrm{m}^{3}\right)$ & N. oleander $\left(\mathrm{m}^{3}\right)$ \\
\hline February & Sheared & $0.19 \pm 0.01$ & $0.55 \pm 0.03$ \\
& Control & $1.05 \pm 0.06$ & $2.86 \pm 0.15$ \\
June & Sheared & $0.31 \pm 0.03$ & $0.89 \pm 0.07$ \\
& Control & $2.25 \pm 0.15$ & $5.26 \pm 0.34$ \\
\hline
\end{tabular}

${ }^{z}$ Values are treatment means $\pm \mathrm{sE} ; \mathrm{n}=12$ and 6 for frequently sheared and unpruned control shrubs, respectively.

Table 2. Effect of frequent shearing on net carbon assimilation (A) and leaf conductance $\left(g_{\mathrm{s}}\right)$ of Leucophyllum frutescens var. green cloud and Nerium oleander 'Sister Agnus' and shrubs during Feb. and June 2001.

\begin{tabular}{|c|c|c|c|c|c|}
\hline \multirow[b]{2}{*}{ Month } & \multirow[b]{2}{*}{ Treatment } & \multicolumn{2}{|c|}{ L. frutescens } & \multicolumn{2}{|c|}{ N. oleander } \\
\hline & & $\begin{array}{c}\mathrm{A} \\
\left(\mu \mathrm{mol} \cdot \mathrm{m}^{-2} \cdot \mathrm{s}^{-1}\right)\end{array}$ & $\begin{array}{c}g_{\mathrm{s}} \\
\left(\mathrm{mmol} \cdot \mathrm{m}^{-2} \cdot \mathrm{s}^{-1}\right)\end{array}$ & $\begin{array}{c}\mathrm{A} \\
\left(\mu \mathrm{mol} \cdot \mathrm{m}^{-2} \cdot \mathrm{s}^{-1}\right)\end{array}$ & $\begin{array}{c}g_{\mathrm{s}} \\
\left(\mathrm{mmol} \cdot \mathrm{m}^{-2} \cdot \mathrm{s}^{-1}\right)\end{array}$ \\
\hline \multirow[t]{2}{*}{ February } & Sheared & $9.9^{\mathrm{z}} \mathrm{ab}^{\mathrm{y}}$ & $247.0 \mathrm{ab}$ & $8.2 \mathrm{a}$ & $128.3 \mathrm{a}$ \\
\hline & Control & $7.5 \mathrm{bc}$ & $256.1 \mathrm{a}$ & $3.0 \mathrm{~b}$ & $46.3 \mathrm{~b}$ \\
\hline \multirow[t]{2}{*}{ June } & Sheared & $10.9 \mathrm{a}$ & $223.4 \mathrm{~b}$ & $10.1 \mathrm{a}$ & $123.5 \mathrm{a}$ \\
\hline & Control & $6.7 \mathrm{c}$ & $96.5 \mathrm{c}$ & $4.7 \mathrm{~b}$ & $60.6 \mathrm{~b}$ \\
\hline Month & & NS & $<0.0001$ & 0.0262 & NS \\
\hline Pruning & & $<0.0001$ & $<0.0001$ & $<0.0001$ & $<0.0001$ \\
\hline Month $\times$ pruning & & NS & $<0.0001$ & NS & NS \\
\hline
\end{tabular}

${ }^{\mathrm{z}}$ Values are treatment means; $\mathrm{n}=12$ and 6 for frequently sheared and unpruned control shrubs, respectively.

'Values followed by the same letter within columns are not significantly different, Tukey's honestly significant difference $(P \leq 0.05)$.

NS $=$ nonsignificant. 
plants but was 1.9 times greater for unpruned control plants. Roots of Texas sage had low levels of colonization by AMF (mean = $8.7 \%$ ) with arbuscules and hyphal coils $($ mean $=5.7 \%)$ predominating. Vesicles were rarely observed $($ mean $=1.1 \%)$. Frequent shearing had no effect on percent AMF colonization of Texas sage roots (Table 3 ). The root length colonized by AMF was significantly less for frequently sheared shrubs than unpruned shrubs with the least colonization found in roots harvested from the lower soil depth (20 to $40 \mathrm{~cm}$ ).

For oleander shrubs, frequent shearing had no significant effect on RMD or RLD indicating higher within-treatment variation (Table 4). Although not significantly different $(P \leq 0.05)$, RMD and RLD of sheared oleanders tended to be greater than that of unpruned plants in the lower soil profile (20 to $40 \mathrm{~cm}$ ). Higher levels of AMF colonization were observed in roots of oleander $($ mean $=$ $23.3 \%$ ) than Texas sage with vesicles (mean $=$ $7.8 \%$ ) and arbuscules (mean $=10.8 \%$ ) predominating. Pruning had a stimulatory effect on percent AMF colonization of roots of oleander, but no significant differences were found between the two depths (Table 4). These results were similar to those of Ingleby et al. (2007) who found that severe pruning of Calliandra calothyrsus Meissner trees stimulated AMF colonization. Frequent shearing had no impact on the length of oleander roots colonized by AMF.

Soil respiration and under canopy soil temperatures of all shrubs were higher in June compared with February (Table 5). Soil respiration was also significantly less under canopies of oleander and Texas sage shrubs that were frequently sheared compared with those that were not pruned. During June, soil respiration fluxes under canopies of frequently sheared oleander and Texas sage shrubs were $31 \%$ less than under the canopies of unpruned shrubs.

Short-term fluctuations in soil respiration reflect changes in plant metabolism and carbon allocation (Ryan and Law, 2005). The relationship between soil respiration and soil temperature has been shown to switch from a positive to a negative correlation when soil moisture levels decline from saturation to drought (Ma et al., 2005). In this study, supplemental water was consistently and equally applied to all shrubs. We found that soil respiration of all plants increased from February to June with an associated increase in soil temperature. Therefore, we have strong confidence in concluding that the soil respiratory differences related to pruning treatments was most likely the result of differences in photosynthetic capacity and allocation of photoassimilates to roots independent of soil water availability.

Cultural management practices alter plant growth through changes in carbon source sink relations and subsequent patterns of allocation (Yuan et al., 2009). The authors are aware of no published studies on rates of landscape shrub leaf maturation and senescence, photosynthetic efficiency, and carbon

Table 3. Effect of frequent shearing or no pruning (control) on root mass density (RMD), root length density (RLD), and arbuscular mycorrhizal fungi colonization of Leucophyllum frutescens var. green cloud at two soil depths.

\begin{tabular}{lccccc}
\hline Treatment & $\begin{array}{c}\text { Depth } \\
(\mathrm{cm})\end{array}$ & $\begin{array}{c}\text { RMD } \\
\left(\mathrm{mg} \cdot \mathrm{cm}^{-3}\right)\end{array}$ & $\begin{array}{c}\text { RLD } \\
\left(\mathrm{cm} \cdot \mathrm{cm}^{-3}\right)\end{array}$ & $\begin{array}{c}\text { Colonization } \\
\left(\mathrm{cm} \cdot \mathrm{cm}^{-3}\right)\end{array}$ & $\begin{array}{c}\text { Length colonized } \\
\left(\mathrm{cm} \cdot \mathrm{cm}^{-3}\right)\end{array}$ \\
\hline Sheared & 0 & $0.09^{\mathrm{z}} \mathrm{b}^{\mathrm{y}}$ & $0.37 \mathrm{~b}$ & $8.5 \mathrm{a}$ & $0.03 \mathrm{~b}$ \\
& 21 & $0.06 \mathrm{~b}$ & $0.25 \mathrm{~b}$ & $6.4 \mathrm{a}$ & $0.01 \mathrm{~b}$ \\
Control & 0 & $0.21 \mathrm{a}$ & $0.94 \mathrm{a}$ & $12.8 \mathrm{a}$ & $0.11 \mathrm{a}$ \\
& 21 & $0.11 \mathrm{~b}$ & $0.53 \mathrm{ab}$ & $6.8 \mathrm{a}$ & $0.04 \mathrm{ab}$ \\
Pruning & & $<0.0001$ & 0.0002 & $\mathrm{NS}$ & 0.0037 \\
Depth & & 0.0003 & 0.0135 & $\mathrm{NS}$ & $\mathrm{NS}$ \\
Pruning $\times$ depth & & 0.0365 & $\mathrm{NS}$ & $\mathrm{NS}$ & $\mathrm{NS}$ \\
\hline
\end{tabular}

${ }^{\mathrm{z}}$ Values are treatment means; $\mathrm{n}=12$ and 6 for frequently sheared and unpruned control shrubs, respectively.

'Values followed by the same letter in each column are not significantly different, Tukey's honestly significant difference $(P \leq 0.05)$.

NS $=$ nonsignificant.

Table 4. Effect of frequent shearing or no pruning (control) on root mass density (RMD), root length density (RLD), and arbuscular mycorrhizal fungi colonization of Nerium oleander 'Sister Agnus' shrubs at two soil depths.

\begin{tabular}{lccccc}
\hline Treatment & $\begin{array}{c}\text { Depth } \\
(\mathrm{cm})\end{array}$ & $\begin{array}{c}\text { RMD } \\
\left(\mathrm{mg} \cdot \mathrm{cm}^{-3}\right)\end{array}$ & $\begin{array}{c}\text { RLD } \\
\left(\mathrm{cm} \cdot \mathrm{cm}^{-3}\right)\end{array}$ & $\begin{array}{c}\text { Colonization } \\
(\%)\end{array}$ & $\begin{array}{c}\text { Length colonized } \\
\left(\mathrm{cm} \cdot \mathrm{cm}^{-3}\right)\end{array}$ \\
\hline Sheared & $0-20$ & $0.25^{\mathrm{z}} \mathrm{a}^{\mathrm{y}}$ & $0.85 \mathrm{a}$ & $28.0 \mathrm{a}$ & $0.15 \mathrm{a}$ \\
& $21-40$ & $0.25 \mathrm{a}$ & $0.82 \mathrm{a}$ & $29.6 \mathrm{a}$ & $0.19 \mathrm{a}$ \\
Control & $0-20$ & $0.26 \mathrm{a}$ & $0.95 \mathrm{a}$ & $14.1 \mathrm{~b}$ & $0.11 \mathrm{a}$ \\
& $21-40$ & $0.18 \mathrm{a}$ & $0.65 \mathrm{a}$ & $21.5 \mathrm{~b}$ & $0.10 \mathrm{a}$ \\
Pruning & & NS & NS & 0.0387 & NS \\
Depth & & NS & NS & NS & NS \\
Pruning $\times$ depth & & NS & NS & NS & NS
\end{tabular}

${ }^{\mathrm{z}}$ Values are treatment means; $\mathrm{n}=12$ and 6 for frequently sheared and unpruned control shrubs, respectively.

'Values followed by the same letter in each column are not significantly different, Tukey's honestly significant difference $(P \leq 0.05)$.

NS $=$ nonsignificant.

Table 5. Effect of frequent shearing on soil respiration $\left(\mathrm{R}_{\mathrm{s}}\right)$ and soil temperature $\left(\mathrm{T}_{\text {soil }}, 10-\mathrm{cm}\right.$ depth) from underneath canopies of Leucophyllum frutescens var. green cloud and Nerium oleander 'Sister Agnus' and shrubs during Feb. and June 2001.

\begin{tabular}{lccccc}
\hline Month & Treatment & $\begin{array}{c}\text { L. frutescens } \mathrm{R}_{\mathrm{s}} \\
\left(\mu \mathrm{mol} \cdot \mathrm{m}^{-2} \cdot \mathrm{s}^{-1}\right)\end{array}$ & $\begin{array}{c}\mathrm{T}_{\text {soil }} \\
\left({ }^{\circ} \mathrm{C}\right)\end{array}$ & $\begin{array}{c}\text { N. oleander } \mathrm{R}_{\mathrm{s}} \\
\left(\mu \mathrm{mol} \cdot \mathrm{m}^{-2} \cdot \mathrm{s}^{-1}\right)\end{array}$ & $\begin{array}{r}\mathrm{T}_{\text {soil }} \\
\left({ }^{\circ} \mathrm{C}\right)\end{array}$ \\
\hline February & Sheared & $0.79^{\mathrm{z}} \mathrm{c}^{\mathrm{y}}$ & $19.0 \mathrm{c}$ & $0.72 \mathrm{c}$ & $13.5 \mathrm{~d}$ \\
& Control & $0.90 \mathrm{bc}$ & $18.1 \mathrm{c}$ & $1.04 \mathrm{bc}$ & $15.6 \mathrm{c}$ \\
June & Sheared & $1.15 \mathrm{~b}$ & $31.3 \mathrm{a}$ & $1.13 \mathrm{~b}$ & $26.0 \mathrm{~b}$ \\
& Control & $1.67 \mathrm{a}$ & $28.3 \mathrm{~b}$ & $1.64 \mathrm{a}$ & $28.5 \mathrm{a}$ \\
Month & & $<0.0001$ & $<0.0001$ & $<0.0001$ & $<0.0001$ \\
Pruning & 0.0125 & 0.0254 & 0.0029 & 0.0002 \\
Month $\times$ pruning & & $\mathrm{NS}$ & $\mathrm{NS}$ & $\mathrm{NS}$ \\
\hline
\end{tabular}

${ }^{\mathrm{z}}$ Values are treatment means; $\mathrm{n}=12$ and 6 for frequently sheared and unpruned control shrubs, respectively.

'Values followed by the same letter within columns are not significantly different, Tukey's honestly significant difference $(P \leq 0.05)$.

NS $=$ nonsignificant.

allocation to roots, especially under arid, urban conditions. This study suggests that the effect of frequent shearing on carbon allocation to roots is taxa-specific. Frequent shearing stimulated leaf $\mathrm{A}$ and $g_{\mathrm{s}}$ of both taxa, but this effect was more pronounced for oleander, especially during June.

For oleander, the lowered fluxes of leaf A and $g_{\mathrm{s}}$ of unpruned shrubs, especially during the normally hot season in June, suggest that a higher percentage of canopy area consisted of leaves that were generally older and past physiological optimum capacity compared with sheared shrubs. In contrast, frequent shearing of oleander regenerated the canopy area toward a preponderance of younger, physiologically mature leaves. This in turn might explain why shearing had no apparent negative impact on carbon source allocation to oleander roots and AMF, although sheared oleanders had $\approx 80 \%$ smaller volumes than those shrubs that were not pruned.

For Texas sage, the greater RMD, RLD, root length colonized by AMF, and under canopy soil respiration of unpruned shrubs was likely related to the five to seven times greater shoot volume and commensurate canopy area than shrubs that were frequently sheared. Thus, although fluxes of leaf A and $g_{\mathrm{s}}$ were higher for sheared shrubs than unpruned shrubs, the extent of this difference in regard to carbon allocation to roots was apparently not sufficient enough to compensate for the less shoot volume brought about 
by the frequent removal of the canopy leaf area.

Frequent shearing of shrubs is a common management practice in irrigated landscapes of the arid southwest United States. This research showed that the patterns of carbon allocation to below-ground roots and AMF of oleander and Texas sage shrubs were dissimilar. From these data we may conclude that the rejuvenative capacity and resilience of oleander to the practice of frequent shearing is greater than Texas sage when well-watered. Future assessments of landscape sustainability should include the implementation of infrequent, conservative plant pruning schemes that are tailored to the patterns of vegetative and reproductive growth of individual landscape plant taxa on a landscape site (Martin, 2008). Therefore, we recommend that Texas sage shrubs should not be frequently sheared in arid, southwest landscapes, even under well-watered conditions, because of the adverse effect that this practice can have on fitness of roots and AMF.

\section{Literature Cited}

Bayala, J., Z. Teklehaimonot, and S.J. Ouedraogo. 2004. Fine root distribution of pruned trees and associated crops in a parkland system in Burkina Faso. Agrofor. Syst. 60:13-26.

Cousins, J.R., D. Hope, C. Gries, and J.C. Stutz. 2003. Preliminary assessment of arbuscular mycorrhizal fungal diversity and community structure in an urban ecosystem. Mycorrhiza 12:319-326.

Davidson, E.A., K. Savage, P. Bolstad, D.A. Clark, P.S. Curtis, D.S. Ellsworth, P.J. Hanson, B.E. Law, Y. Luo, K.S. Pregitzer, J.C. Randolph, and D. Zak. 2002. Belowground carbon allo- cation in forests estimated from litterfall and IRGA-based soil respiration measurements. Agr. For. Met. 113:39-51.

Fownes, J.H. and D.G. Anderson. 1991. Changes in nodule and root biomass of Sesbania sesban and Leucaena leucocephala following coppicing. Plant Soil 138:9-16.

Giovannetti, M. and B. Mosse. 1980. An evaluation of techniques for measuring vesicular arbuscular mycorrhizal infection in roots. New Phytol. 84:489-500.

Hanson, P.J., N.T. Edwards, C.T. Garten, and J.A. Andrews. 2000. Separating root and soil microbial contributions to soil respiration: A review of methods and observations. Biogeochemistry 48: 115-146.

Ingleby, K., J. Wilson, R.C. Munro, and S. Cavers. 2007. Mycorrhizas in agroforestry: Spread and sharing of arbuscular mycorrhizal fungi between trees and crops: Complementary use of molecular and microscopic approaches. Plant Soil 294:125-136.

Koske, R.E. and J.N. Gemma. 1989. A modified procedure for staining roots to detect VA mycorrhizas. Mycol. Res. 92:486-505.

Ma, S., J. Chen, J.R. Butnor, M. North, E.S. Euskirchen, and B. Oakley. 2005. Biophysical controls on soil respiration in the dominant patch types of an old-growth, mixed-conifer forest. For. Sci. 51:221-232.

Martin, C.A. 2001. Landscape water use in Phoenix, Arizona. Desert Plants 17:26-31.

Martin, C.A. 2008. Landscape sustainability in a Sonoran Desert city. Cities Environ. Vol. 1, Issue 2. Art. 5:1-16.

Martin, C.A., K.A. Peterson, and L.B. Stabler. 2003. Residential landscaping in Phoenix, Arizona: Practices, preferences and covenant codes and restrictions (CC\&Rs). J. Arbor. 29: 9-17.

McGonigle, T.P., M.H. Miller, D.G. Evans, G.L. Fairchild, and J.A. Swan. 1990. A new method which gives an objective measure of colonization of roots by vesiculararbuscular mycorrhizal fungi. New Phytol. 115: 495-501.

Peter, I. and J. Lehmann. 2000. Pruning effects on root distribution and nutrient dynamics in an acacia hedgerow planting in northern Kenya. Agrofor. Syst. 50:59-75.

Raich, J.W. and K.J. Nadelhoffer. 1989. Belowground carbon allocation in forest ecosystems: Global trends. Ecology 70:1346-1354.

Ryan, M.G. and B.E. Law. 2005. Interpreting, measuring, and modeling soil respiration. Biogeochemistry 73:3-27.

Smith, S.E. and D.J. Read. 1997. Mycorrhizal symbiosis. 2nd Ed. Academic Press, London, UK.

Stabler, L.B. 2003. Ecosystem function of urban plants in response to landscape management. $\mathrm{PhD}$ diss., Arizona State University, Tempe, AZ. Abstr. AAT 3105550.

Stabler, L.B. and C.A. Martin. 2000. Seasonal patterns of plant water status and gas exchange in two Sonoran Desert landscapes. Ecol. Soc. Amer. 85:211.

Stabler, L.B., C.A. Martin, and J.C. Stutz. 2001. Effect of urban expansion on arbuscular mycorrhizal mediation of landscape tree growth. J. Arbor. 27:193-200.

Whitcomb, S.A. and J.C. Stutz. 2007. Assessing diversity of arbuscular mycorrhizal fungi in a local community: Role of sampling effort and spatial heterogeneity. Mycorrhiza 17:429-437.

Wildy, D.T. and J.S. Pate. 2002. Quantifying above-ground and below-ground growth responses of the western Australian oil mallee, Eucalyptus kochii subsp. plenissima, to contrasting decapitation regimes. Ann. Bot. (Lond.) 90:185-197.

Yuan, J.H., Z.W. Dai, J.Y. Zhao, and S.H. Li. 2009. Distribution of newly fixed ${ }^{14} \mathrm{C}$-photoassimilate under deficit irrigation and half-root stress in peach trees. Plant Sci. 177:691-697. 